\title{
Protection and Development of Hainan Li Dance under the Background of Cultural Power
}

\author{
Xiaoqin Ouyuang ${ }^{1,2, a}$ and Jiafa Wang ${ }^{2, b^{*}}$ \\ ${ }^{1}$ School of art, Hainan Tropic Ocean University \\ ${ }^{2}$ School of Education, Hainan Tropic Ocean University \\ aouyangdata@163.com, bwangjf168@163.com \\ *The corresponding author
}

\section{Keywords: Li nationality; Dance; Aesthetic culture; Protection and development}

\begin{abstract}
Hainan Li dance is one of the important resources in our national dance culture treasure-house and is also the art with the most national features in Li aesthetic culture. This paper focuses on the analysis of Li dance features, and discusses the way to protect and develop Hainan $\mathrm{Li}$ dance under the time background.
\end{abstract}

\section{Introduction}

Hainan is a multi-ethnic province. In 56 nationalities of China, more than 30 live in Hainan, including Li, Miao, Hui, Han, etc. For a long time, all kinds of national culture, production and living ways, and diverse ecological environment are blended together, gradually forming the different nationalities, traditional culture features of different branches and folk customs, as well as Hainan rich and colorful ethnic traditional culture and art, and the most distinctive one is Li dance.

Hainan $\mathrm{Li}$ dance has rich contents and various forms, as well as plain and vivid feature and strong flavor of life, reflecting profound ethnic features. It is not only an art representing the development, production and life of Huainan Li nationality for thousands of years, but also a bright pearl in the hall of Chinese even the world's art culture, as well as precious spiritual wealth and culture achievements of human.

As China's largest special economic zone, the politics, economy and culture of Hainan has entered into the passage of rapid development since the construction of international tourism island was put forward. Unique Li dance has tremendous development opportunities and also faces a severe test of various kinds of culture shock. The problems including inheritor dislocation, loss of cultural heritage sites, as well as the plight resulted from function transformation have restricted and affected the survival and development of Hainan Li dance. Under the background of cultural power, how to protect the development of Hainan Li dance and let it make more contribution in the construction of international tourism island and beautiful China is an important subject worthy of attention and research.

\section{Features of Hainan Li Dance}

$\mathrm{Li}$ is one of the main minorities in Hainan. They live in the central Wuzhishan area and the southwest area from generation to generation and now the population is more than 1.3 million. Li nationality is good at singing and dancing, and on each March $3^{\text {rd }}$ and other festivals, the most important celebration for the men and women is to sing and dance even for one night, which ${ }^{[1]}$ just indicates Li nationality created valuable folk dance for the human art treasure house in long-term production, living and entertainment and other social practice.

Hainan Li dance originated from various recreational activities during production with conscious processing, refining and adapting and eventually became an art form. According to the nature and culture connotation, the dance can be divided into religious ritual dance, living customs dance, entertainment and celebration dance, production dance and heroic struggle dance, totally five major cultural types [2]. The representative dances include dozens of dances: Dachai dance, Xiandeng 
dance, Turtle Shell dance, Zouluo dance, Tiaoluo dance, Zhaozu dance, ZhaohunGangui dance, Laogu dance, Jizu dance, Gangui dance, Wufang dance, Qianling dance, Daomi dance, Daguan dance, Tiaogu dance and so on. Through flexible use of dance language, rhythm, expression and composition and other basic elements, it creates a beautiful, intuitive and full dance image, and expresses various complex and true ethnic feelings. It deeply roots in the special ecological environment, cultural background and social history, with full extraction of Li nationality language, folk customs, history and culture, religious belief and so on. [3] Li dance carries rich and profound cultural connotation of Li nationality in ecological environment, beliefs, social history, etc., so it has important value of history, art and culture.

Hainan Li dance has its unique ethnic flavor and feature, in summary, there are three features:

Come from Life, and Deeply Root in the Traditional Culture of Li Nationality. Hainan Li dance forms in the specific geographical environment and living conditions of Hainan through long-term selection, development and accumulation. [4] From the performance and expression, it covers and presents various aspects of Li nationality from production and living to resisting struggle, from festival entertainment to praying and blessing, from marriage and birth religion, from economic life to history and culture and almost all aspects. Li dance is a kind of culture saturated with $\mathrm{Li}$ people's spirit, personality and soul. [5] $\mathrm{Li}$ dance is created from life, reflecting and recording life, where the beauty of life is presented by actions. It is also the typical carrier of $\mathrm{Li}$ aesthetic culture, to this extent, $\mathrm{Li}$ dance is an "encyclopedia" comprehensively recording and reflecting Li people's social life, history and culture, and also the hotspot of Li people's aesthetic culture. Through Li dance-especially those time-honored dances handed down orally from father and son, master and apprentice, we can observe visually and understand the politics, economy, culture and other aspects of the original ecological information from them.

Taking Dachai dance for example, Hainan Dachai dance is the typical aesthetic culture activity, which is known by all Hainan folk and well known to the outside world. It originates from the ancient Li funeral ceremony, and becomes popular in Hainan folk sports entertainment activities later. It has a long history and is produced in Li people's production and life, carrying the historical memory and wisdom of thousands of years, the philosophy and aesthetics of Li people.

Dachai dance can be performed by taking advantage of simple materials like wood or bamboo as the activity instruments and with four people, a few bamboo sticks, a patch of space, the dance can be started. The dancers of Dachai dance can be divided into firewood collection team and firewood jumping team. Firewood team dances with zigzag, "\#” type and fan type, and the jumping team can join in it with various interesting footwork. The dance steps are vivid and interesting, and its contents have two main categories. The first one is to simulate the production scene of Li people working, and the steps include sharpening knife step, sieving rice step, twisting step, etc. Through a variety of visual actions, Dachai dance presents Li people's production and living scenes vividly, showing their unique social evolution in the natural environment around with mountains and forest, and the cultural ecological environment with optimistic solidarity and collaboration and singing and dancing skills, as well as the evolution of Hemu system and clan society. Another content of Dachai dance is an imitation of various animal movement forms, and the steps have little frog, deer leapfrog, monkey jump, etc. These actions also carry strong Li aesthetic culture and concepts, for example little frog step directly reflects the primitive consciousness and aesthetic ideology for frog totem worship that has formed since from the primitive society.

Li nationality only has language but no words, so Li dance is an important symbol to record the aesthetic culture and civilization history. In addition to Dachai dance, local people's indigenous religion, funeral culture, customs and habits, etc. are also fully recorded and circulated in other $\mathrm{Li}$ dances. People that need to study the features of Hainan primitive religion can study Hainan folk "Zhuogui dance", "Wufeng dance", "Nuo dance"; by studying "Blessing dance", "Nian dance" (also called "PingAn dance"), Hainan festival features under "Hemu system" economy can be seen; by studying "Laogu" dance, people can learn the male genitalia worship of Li society of male and the importance of male in the human reproduction, etc. There are a lot of other Li dances with various functions. For example, a blessing dance played by children is called "bowl dance", which 
is used to remember ancestors and the national hero; "Tachun dance" is used in the romance of young men and women; "Monkey dance" is a kind of folk dance with strong entertainment. Besides, there are some dances presenting $\mathrm{Li}$ people's production and living entertainment, such as "Chongmi dance", "Zhuoniao dance", "Qianchuan dance" and so on. These dances lively reflect Li people live in harmony with nature from the ancient times, and show some folk culture and national features in the process of struggling with disasters. [6]

Innovating and Adopting Aesthetics Elements from the Times. The sea admits hundreds of rivers for its capacity to hold. Hainan Li dance not only roots in the national and regional cultural life, retaining its own features, also learn the essence of from other ethnic groups and the times widely, creating new national dance for arts gardens, to display its own unique value and endless charm advancing with the times.

Li dance derives from the ethnic life and forms after conscious purification and concise summary, so it has both strong aesthetic features and national style, and distinct features of the times.

Straw hat is not only the typical items in Li people's daily life, but also is an important symbol of traditional costume culture and customs. The choreography of "Straw hat dance" caught the creative inspiration from the working scene of $\mathrm{Li}$ girl, using the necessary daily life tool straw hat as the symbol props to present Li production, innovating boldly in action words and adding all kinds of music effect, allowing Li dance combining with the elements of the times, integrating natural dancing scene into the flexible dancing posture, to create the most classic dancing movements of sideways three bending in Li dance. It is exactly the close integration of ethnic artistic features and various aesthetic elements finally making "Straw hat dance" achieve great success and become one of the representatives of China's national dance. In 1994, this dance stood out from the numerous national dances in the "20th Century Chinese Classical Dance" competition and won the champion [7]. The achievement sideways three bending dancing movement that was created by the modern artist combining the ethnic traditional action with the aesthetic features of the time has become one of the most important, famous and classic dancing movement of Hainan Li dance.

"Chongmi dance" and "Dachai dance" are also the classic dances with perfect combination of traditional Hainan Li dance potential and wide elements of the time after reworking.

In addition, Li dance also widely absorbs the elements of other cultures to enrich itself. By actively absorbing the Taoism culture, its own unique form of folk dance is created. For example, the "Nuo dance" circulating in Qiongzhong, Sanya is different from other parts of China from the posture, modeling, movement rule, etc. It's the localization result of Nuo dance in Hainan, so it has rich features of Hainan.

Influencing the World and Becoming the Name Card to Present Hainan Ethnic Aesthetic Culture. There are many nationalities good at dancing in 56 nationalities of China, although Li nationality is only one of them and locates in relatively backward Hainan, it has the most original unique artistic charm, since stepping out of Hainan and of China, it has a huge influence soon and becomes an international tourism name card showing national aesthetic culture of Hainan island.

Hainan $\mathrm{Li}$ dance came to prominence on the world stage through $\mathrm{Li}$ dance "March $3^{\text {rd }}$ " performed in 1957 the 6th World Youth Festival, and Li dance art attracted great attention this time. Since then, in 1962, "the mother of Li dance" Chen Qiao created "Straw hat dance" which won the gold medal of the $8^{\text {th }}$ World Youth and Student Peace Friendship Dance Competition held in Helsinki, Finland, and in 1994, it won the champion of "20th Century Chinese Classical Dance" competition [8]. From then on, in China and even global folk dance world, Hainan Li dance art has a certain influence. In Hainan folk dance, "Dachai dance" attracts the most attentions. Because it's the oldest and the most representative Li dance, it is praised as a "living fossil" of Li dance and becomes China's first batch of national intangible cultural heritage protection projects.

With the course of Hainan building international tourism island, "cultural power" proposed in the eighteenth National People's Congress put forward Hainan Li dances, including "Dachai dance", "Chongmi dance", "Qianlingshuangdao dance", "Straw hat dance" and so on, play a more and more important role in cultural construction and their unique features show Hainan aboriginal culture and connotation. Nowadays, not only in the professional arena, also in scenic spots, hotels, 
Hainan Li dance is showing the unique folk customs in Hainan to visitors.

The folk dance located in a remote Miao village creates the unique folk features of Hainan with the perfect combination of its flexible dance movement and ethnic costumes. It has been out of the Hainan and the country, and even walked to the stages of the world, which reveals the powerful cultural forces of Hainan Li dance.

\section{The Protection and Development Approach of Hainan Folk Dance}

Protect and Develop Li Dance in the Ecological Construction. Art comes from life and life is the source of artistic inspiration. As a kind of ethnic inheritance art, Li dance needs to have a good ecological cultural space. With the process of modern construction, the ecological environment of Li dance is facing with a lot of troubles: firstly, the original villages, unique mountains and rivers and other natural environment has very big change, the suitable places for folk dance performances are reducing and disappear, and thus affect the development and circulation of Li folk dance. Secondly, the mode of Li people's production and living has a big change. With the speeding up of urbanization process, people's pace of life become tighter, from time to space, so the inheritance of ancient $\mathrm{Li}$ culture for young people is facing many difficulties. Many old Li dances and accompaniment instruments are facing with the embarrassment of being lost. Farming culture is also corroded by urban culture, which seriously affects the protection and development of Li dance.

In the cultural ecology construction of Li culture, we should not only pay much attention to the natural environment of Li village, folk customs, activity places, especially performance venues protection for $\mathrm{Li}$ folk dance, but also should attach importance to education and research organization for Li dance development, have industrial consciousness of Li dance culture, intensify the study of folk dance, and use school and other education institutions to popularize dance culture of Li nationality. [9] Li dance should be protected and developed in good cultural ecology.

Protect and Develop Li Dance in Economic Construction. Hainan Li dance has important social significance and cultural value. Under the time background, due to the impact of foreign culture, Li dance should be protected and developed. The primary measure is to request the culture department and other related government departments increasing the awareness and do a good job of protecting $\mathrm{Li}$ dance in the economic construction.

In the process of building Hainan international tourism island, government and organizations should correctly understand and treat the protection and development of $\mathrm{Li}$ dance and make scientific development plan for the folk Li dance resources, improve the support for Li dance study; at the same time, culture is also a kind of productivity, so Li dance is also an important resource to propagandize Hainan and develop the economy. The revitalization of traditional ethnic dance should be combined with local economic development, rescuing and exploring the key resources to promote the protection and development of $\mathrm{Li}$ dance in use. Hainan government and organizations should enhance the support of ethnic traditional festivals by using the traditional festivals like March $3^{\text {rd }}$ Festival, Folk Song Festival, Happiness Festival and so on, enhancing the publicity and promotion of Li dance art, actively support and build Li dance brand. Promote the development of Li dance industrialization, broaden the development channels and improve the art quality, thus pushing Li dance to moves towards the whole country and the world.

Protect and Develop Li Dance in Collection and Innovation. Hainan Li dance is an ancient and young art. The protection and development of $\mathrm{Li}$ dance should combine inheritance and positive innovation. Hainan should increase the project investment for $\mathrm{Li}$ dance to promote, encourage, lead and support institutions and scholars to collect and study Li dance.

Firstly, strengthen the study and collection of Li dance. Hainan Li dance resources should be collected and studied according to the plan, and the original ancient dance should be explored urgently in the form of video and photo. The study of Li dance is required to be close to the folk and their lives, striving to get the essence.

Secondly, pay attention to the innovative research of Hainan Li dance. Based on the tradition and unique features, absorb nutrients from the times widely with positive innovation, pursuing the new and change. Based on respecting and preserving the traditional dance features, the era art research 
results are adopted and used, with modern creative skills to add the flavor of the times, to let this ancient art Li dance coruscate the luster of the times, showing the artistic charm of perfect combination of traditional art and modern means.

\section{Conclusion}

Hainan Li dance is the precious treasure in the treasure house of Chinese traditional culture. In the process of building Hainan international tourism island, we should raise awareness, and take measures to [10] protect and develop $\mathrm{Li}$ dance well, let one of the colorful $\mathrm{Li}$ aesthetic culture $\mathrm{Li}$ dance art show the splendidness, and the beauty soul of Li dance shine forever.

\section{Acknowledgements}

Fund project: one of the research results of 2014 national social science fund project "Li Aesthetic Cultural Study" (14 xzx022).

\section{References}

[1] H.B. Wang. Implication Perspective on Modeling, Ecology, Symbol-Hainan Li Women Dress Culture (Minzu University of China 2009)

[2] B. Lu. Discussion on the National Dancing Education Value: Journal of Popular Songs, (2012) No. 6, p. 17.

[3] X.Q. Liu. Hainan Runfangyan Li Dress Culture Research (Beijing Institute of Clothing Technology, China 2012) p. 24.

[4] J. Yang. The Origin and Development of Hainan Li Drum Dance: Art Education (2014) No.(7)

[5] Z.Q. Gao. Prevue of Li Dance Type: Journal of Beijing Dance Academy (2002) No.2, p. 42-46.

[6] Y.J. Yue. Education Anthropology Research of Hainan Li Dachai Dance Cultural Heritage (Minzu University of China 2008)

[7] L.N. Sun. Appreciation and Analysis of Straw Hat Dance: Journal of Big Stage (2012) No.7, p.99-100.

[8] X.C. Zhao. Straw Hat Dance: Journal of Dance, (2009) No. 8, p. 38-39.

[9] D.H. Huang. Introduction of Li Folk Dance Culture Characteristic and Practical Application in Teaching: Grand View Weekly, (2012) No. 12, p. 177-178.

[10]L.H. Chen, S.G. Yu, Preface of China Li Study: Journal of Qiongzhou University, 2012 No. 4, p. 5-9.

\section{Author Introduction}

The first author: Xiaoqin Ouyang, (1966 -), born in Shaoyang vice president of Hainan Tropical Ocean University College of Art, dance professor, research direction: folk dance.

Corresponding author: Jiafa Wang (1955 -), born in Lingshui Hainan, dean of Hainan Tropical Ocean University College of Education, literature professor, national social science fund gainer. Research direction: Having deep study and achievements on aesthetics of literature and art, especially the study on literature and art theory teaching material, turning to folk aesthetics research in recent years. 